\title{
Genome-Wide Analysis of Gene Expression in Ralstonia solanacearum Reveals That the hrpB Gene Acts as a Regulatory Switch Controlling Multiple Virulence Pathways
}

\author{
Alessandra Occhialini, ${ }^{1}$ Sébastien Cunnac, ${ }^{1}$ Nancie Reymond, ${ }^{2}$ Stéphane Genin, ${ }^{1}$ and \\ Christian Boucher ${ }^{1}$ \\ ${ }^{1}$ Laboratoire des Interactions Plantes-Microorganismes, INRA-CNRS, UMR2594, BP 52627, 31326 Castanet tolosan \\ Cedex, France ; ${ }^{2}$ Biologie Fonctionnelle, Insectes et Interactions (BF2I), UMR INRA/INSA de Lyon, 69621 Villeurbanne, \\ France
}

Submitted 31 March 2005. Accepted 7 May 2005.

\begin{abstract}
A 70-mer oligonucleotide-based DNA microarray covering 5,074 of the 5,120 predicted genes from Ralstonia solanacearum has been generated and used to investigate the repertoire of genes that are under the control of the transcription activator $\mathrm{HrpB}$, which governs pathogenicity in this plant pathogenic bacterium. This study identified 143 hrpB up-regulated genes and 50 hrpB down-regulated genes. In addition to extending the repertoire of type III effector proteins with 26 new candidates, this work demonstrates that the $h r p B$ regulon extends beyond type III secretion system-related functions to include a number of genes governing chemotaxy, biosynthesis or catabolism of various low-molecular-weight chemical compounds, and siderophore production and uptake. The presence of several transcripttional regulators and a cluster of genes predicted to encode the synthesis of an acylhomoserine lactone together with the absence of a consensus $h r p_{I I}$ box in the promoter of a significant proportion of the $h r p B$-regulated genes suggest that, for some genes, $h r p B$ regulation might be indirect. Altogether, the data indicate that $h r p B$ acts as a master regulatory gene governing a physiological swing associated with the shift from saprophytic to parasitic life.
\end{abstract}

Ralstonia solanacearum is a gram-negative $\beta$-proteobacterium pathogenic to plants and responsible for the development of bacterial wilt, a severe and devastating plant disease affecting over 200 plant species (Hayward 2000; Prior et al. 1997). Wilting symptoms occur as a consequence of an intensive multiplication of the bacteria within xylem vessels and are associated with the production of copious amounts of exopolysaccharides that act by blocking water traffic in the plant. Molecular and genetic approaches have identified a wide range of genes and functions that play a role in the establishment and multiplication of the bacterium within plant tissues leading to development of the disease (Genin and Boucher 2004; Schell 2000). Such studies have also identified a large set of regulatory

Corresponding author: C. Boucher; Telephone: +33 5612654 16; Fax: +335612650 61; E-mail: boucher@toulouse.inra

* The $\boldsymbol{e}$-Xtra logo stands for "electronic extra" and indicates the HTML abstract available on-line contains a supplemental table that lists the primers used in this study and is not included in the print edition. genes governing pathogenicity and have demonstrated that these genes are organized in complex regulatory networks (Schell 2000). Large-scale gene transcription analyses have revealed that many proteins that act in concert are coregulated at the transcriptional level (Grigoriev 2001; Laub et al. 2000). Therefore, genes that are coregulated together with core pathogenicity genes could also be involved in the plant infection process.

Although complete sequences of the genomes of several plant pathogenic bacteria are now available (Plano 2004; Van Sluys et al. 2002), very few studies have sought to make an exhaustive search for the target genes of a transcriptional regulator involved in the control of pathogenicity (Fouts et al. 2002; Noël et al. 2001; Zwiesler-Vollick et al. 2002). In $R$. solanacearum, the widest study toward this goal concerns the definition of the $h r p B$ regulon. The $h r p B$ gene encodes a positive activator required for the transcription of other $h r p$ genes that are involved in the production of a type III secretion system (TTSS), a key pathogenicity determinant, since mutants deficient in the corresponding hrp genes are no longer able to cause disease (Alfano and Collmer 2004; Buttner and Bonas 2002). As in many pathogens of plants, animals, or humans, the $R$. solanacearum TTSS allows injection of bacterial proteins, called effectors, into plant cells upon contact of the bacteria with host tissues (Aldon et al. 2000; Cunnac et al. 2004b; Genin and Boucher 2004). The HrpB protein also acts as a positive activator required for the transcription of the effector protein genes (Cunnac et al. 2004b; Guéneron et al. 2000), and a recent study identified a consensus motif called the $h r p_{I I}$ box in the promoters of $h r p$ and several effector genes (Cunnac et al. 2004a). A systematic search for this consensus in the promoter region of all $R$. solanacearum genes led to the identification of a set of new candidate effector genes (Cunnac et al. 2004b). On the other hand, other candidate effector genes have been identified as being part of the $h r p B$ regulon, although they lack a $h r p B_{I I}$ box in the promoter, indicating that the search for this motif is not sufficient and that additional genes remain to be identified (Cunnac et al. 2004b).

Here, we report the construction of a microarray covering almost all of the genes identified in strain GMI1000 of $R$. solanacearum and on its use for transcriptome analysis, in order to produce an exhaustive view of $h r p B$-regulated genes and functions. 


\section{RESULTS}

Construction of a $R$. solanacearum DNA microarray and experimental design.

A microarray consisting of 5,086 long oligonucleotides deposited in duplicate and representing 5,074 of the 5,120 predicted protein-coding genes identified in the genome of strain GMI1000 of $R$. solanacearum was constructed. The missing oligonucleotides correspond to IS elements already present on the array or to very short putative genes for which an appropriate oligo could not be designed. This microarray also includes three oligonucleotides corresponding to the nontranscribed strand of three genes from $R$. solanacearum GMI1000 (RSp0855, RSp0860, and RSp0861), 10 oligonucleotides corresponding to five Corynebacterium glutamicum genes that can be used as possible "spike" controls, and 26 additional controls consisting of oligonucleotides that do not match with any GMI1000 genomic sequence. In addition, the microarray also includes a set of "blank" controls in which buffer without oligonucleotides was spotted.

\section{The hrpB gene acts both \\ to activate and repress gene expression.}

In order to characterize the $h r p B$ regulon, the transcriptome of the wild-type strain GMI1000 was compared with the transcriptome of a $h r p B$-deficient derivative GMI1525 (Table 1). This analysis revealed 111 genes that are down-expressed in the $h r p B$ mutant, including 55 of the $70 \mathrm{brg}$ genes ( $h r p B$-regulated genes) that had previously been identified (Cunnac et al. 2004b; Genin et al. 1992; Guéneron et al. 2000). Of the 56 newly identified genes, 44 of the $h r p B$ up-regulated genes thus defined belong to 17 putative operons, whereas the remaining genes are most likely monocistronic. A total of 18 of the 56 new genes are preceded by a $h r p_{I I}$ box. Three other genes might belong to multicistronic $h r p_{I I}$ box-harboring operons, and 12 are preceded by an imperfect $h r p_{I I}$ box (TTCGN ${ }_{16}$ TTCG with one mismatch allowed). For the 22 remaining ones, no $h r p_{I I}$ box is present in the region spanning 500 base pairs upstream of the start codon of the cognate gene or of the first gene of the operon. These experiments also identified one gene, RSp0785, whose transcription was down-regulated by $h r p B$, i.e., at least four times higher in the $h r p B$ mutant as compared with the wild-type strain.

\section{Transcriptome of a strain expressing $h r p B$ at a high level reveals additional genes whose expression is controlled by HrpB.}

Transcription of $h r p B$ is increased when bacteria are in contact with plant cells, and this induction results in increased transcription of $h r p B$ up-regulated genes (Aldon et al. 2000; Marenda et al. 1998). This plant signaling effect is at least partly mimicked at the transcriptional level by introduction of the plasmid pAM5, which carries a cloned copy of $h r p B$, into strain GMI1000 (Guéneron et al. 2000). This strategy has already been used to demonstrate $h r p B$-dependency for certain lowly expressed genes for which this trait was difficult to establish by comparing the $h r p B$ mutant to the wild-type strain (Cunnac et al. 2004b). Therefore, we compared gene expression in strain GMI1728, a GMI1000 derivative that carries pAM5, with that of the hrpB-deficient mutant GMI1525(pLAFR3), which carries the corresponding empty vector. Columns 4 and 5 of Table 1 show the results of these experiments and confirm the $h r p B$-dependency for 101 of the 111 previously identified genes. In addition, these experiments identified 32 additional $h r p B$ up-regulated genes. A total of 16 of these additional genes were detected in the previous experiment but were not selected, since the $\log _{2}$ value of their induction ratio was lower than 2 (column 2 of Table 1) when strains GMI1000 and GMI1525 were compared. Moreover, 18 of the 32 genes harbor a $h r p_{I I}$ box (allowing one mismatch) in their promoter. The 32 additional genes include nine of the 15 known $h r p B$-regulated genes that were not detected when comparing the transcriptomes of strains GMI1000 and GMI1525.

A total of $48 \mathrm{hrpB}$ down-regulated genes were identified. For eight of these genes, repression was also observed in the previous experiment with a cutoff $P$ value of 0.05 . Reciprocally, repression of Rsp0785, which was observed when comparing GMI1000 and GMI1525, is also detected in the comparison between the $h r p B$-deficient mutant and the $h r p B$-overexpressing strain with a $P<0.05$ cutoff threshold. The majority of these HrpB-repressed genes are organized in putative operons.

Finally, four genes, organized in two putative adjacent operons (RSc1804 to RSc1805 and RSc1807 to RSc1808), had a particular behavior, since they were $h r p B$ up-regulated in the comparison of GMI1000 with GMI1525 and down-regulated when $h r p B$ was overexpressed.

Put together, the data obtained from the two sets of experiments allowed the distinction of four classes of genes based on their regulation patterns and on the structure of their promoters (Table 1). Class I and Class II genes correspond to genes whose transcription is up-regulated by $h r p B$ in at least one of the two experimental conditions tested. Class I genes have a $h r p_{I I}$ box in the promoter, whereas Class II genes do not and could be regulated by $h r p B$ in an indirect manner. We were unable to identify a common motif in the promoters of Class II genes. Class III genes include genes whose transcription is directly or indirectly repressed by $\mathrm{HrpB}$, and the four remaining genes were grouped into Class IV. These genes require $h r p B$ for induction but are repressed when $h r p B$ transcription is increased.

Validation of the $h r p B$-dependency of representative genes.

In order to validate the data from the transcriptome analysis, the lacZ reporter gene from Escherichia coli was transcriptionally fused with seven genes from classes I and II, encoding candidate type III effectors, as predicted on the basis of the biased amino acid composition of the 50 residues located at the $\mathrm{N}$ terminus of the corresponding proteins (Cunnac et al. 2004b). Expression of the resulting gene fusions was compared in wild type and in a $h r p B$-deficient or $h r p B$ overexpressing background of $R$. solanacearum. As shown in Table 2, the resulting data clearly confirmed that transcripttion of these genes is dependent on the presence of a functional $h r p B$ gene.

In a complementary set of experiments, semiquantitative reverse transcriptase-polymerase chain reaction (RT-PCR) experiments were conducted on mRNA populations obtained from the wild-type strain GMI1000, from the $h r p B$-deficient mutant GMI1525 and from strain GMI1728 (i.e., overexpressing $h r p B$ ). The data presented in Figure 1 and summarized in column 10 of Table 1 demonstrate the $h r p B$-dependent regulation for 28 of the 32 genes tested and confirm the negative regulatory effect of $h r p B$ on expression of genes from Class III. Concerning Class IV genes, although the hrpB-dependent transcription of Class IV gene RSc1807 was confirmed, no repression was observed when multiple copies of $h r p B$ are present in the strain. However, the fact that two genes from the same bicistronic operon have a common gene expression pattern is a good indication that Class IV actually corresponds to a specific pattern of regulation.

Because the present study is the first one to establish a negative regulatory function for $h r p B$ and because it is also the first time we identify $h r p B$-regulated genes that encode proteins not associated with TTSS functions, quantitative RT-PCR was 
Table 1. Summary of $h r p B$-regulated genes identified based on transcriptome analysis ${ }^{\mathrm{a}}$

\begin{tabular}{|c|c|c|c|c|c|c|c|c|c|}
\hline Gene ID & $\begin{array}{c}1000 / 1525 \\
\text { ratio }^{\mathbf{b}}\end{array}$ & $\begin{array}{c}P \text { - } \\
\text { value }\end{array}$ & $\underset{\text { ratio }^{\mathrm{b}}}{\operatorname{pam5/1525}}$ & $\begin{array}{c}\text { P- } \\
\text { value }\end{array}$ & $\begin{array}{l}\operatorname{hrp}_{I I} \\
\text { box }^{\mathbf{c}}\end{array}$ & $b r g$ genes $^{\mathrm{d}}$ & $\begin{array}{l}\text { Export } \\
\text { signal }^{\mathrm{e}}\end{array}$ & $\begin{array}{l}\text { Corresponding protein or } \\
\text { predicted function }^{\mathrm{f}}\end{array}$ & $\begin{array}{c}\text { RT-PCR } \\
\text { validation }\end{array}$ \\
\hline \multicolumn{10}{|c|}{ Class 1} \\
\hline RSc0041 & 1.92 & 0.000 & 2.19 & 0.000 & +* $^{*}$ & & 3 & Hypothetical / Unknown & \\
\hline RSc0245 & 3.22 & 0.000 & 3.59 & 0.000 & + & + & 3 & TTSS-efflector RipB & \\
\hline RSc0608 & 738 & 0.000 & 6.84 & 0.000 & + & + & 3 & TTSS-effector AvTA & \\
\hline RSc0609 & 4.65 & 0.017 & 1.56 & 0.000 & in operon? & & 0 & Hypothetical / Unknown & \\
\hline RSc0616 & 6.95 & 0.000 & 8.05 & 0.000 & in operom? & & 0 & Hypothetical / Unknown & 2 \\
\hline RSc0617 & 6.69 & 0.000 & 7.94 & 0.000 & + & & 1 & Hypothetical / Unknown & 2 \\
\hline RSC0824 & 1.73 & 0.023 & 2.39 & 0.000 & $+^{*}$ & & 1 & Conserved hypothetical protein & \\
\hline RSc0825 & 2.16 & 0.000 & 3.98 & 0.000 & $*^{*}$ & & 2 & Hypothetical / Unknown & \\
\hline RSc0826 & 1.73 & 0.000 & 3.60 & 0.000 & + & & 3 & TTSS-eflector PopP1 & \\
\hline RSC0868 & 3.39 & 0.004 & 4.28 & 0.000 & + & + & 3 & TTSS-effector PopP2 & \\
\hline RSC0894 & 7.01 & 0.000 & 7.46 & 0.000 & $+^{*}$ & & 1 & Hypothetical / Unknown & 1 \\
\hline RSC0895 & 4.18 & 0.000 & 3.88 & 0.000 & + & & 0 & Partial homology to Pantoea agglamerans pw. gypsophi & 2 \\
\hline RSC1349 & 2.61 & 0.001 & 305 & 0.000 & + & + & 3 & Partial homology to Salmonefla TTSS-effector SspHII & \\
\hline RSc1356 & 4.22 & 0.001 & 4.62 & 0.000 & + & + & $\frac{2}{3}$ & TTSS-effector Ripg (LRR protein, GALA subfamily) & \\
\hline RSc1357 & 600 & 0.000 & 6.84 & 0.000 & + & + & 3 & LRR protein, GALA subfamily & \\
\hline RSc1388 & 3.07 & 0.000 & 3.72 & 0.000 & $+^{*}$ & + & 3 & Hypothetical / Unknown & 1 \\
\hline RSc1474 & 5.74 & 0.000 & 6.60 & 0.000 & + & + & 0 & Hypothetical / Unknown & \\
\hline RSc1475 & 321 & 0.000 & 4.06 & 0.000 & + & + & 3 & Hypothetical / Unknown & \\
\hline RSc1800 & 5.50 & 0.000 & 6.18 & 0.000 & + & * & 3 & LRR protein, GALA subfamily & \\
\hline RSC1801 & 1.43 & 0.001 & 222 & 0.000 & + & + & 3 & LRR protein. GALA subfamíy & \\
\hline RSC2101 & 1.57 & 0.001 & 4.00 & 0.000 & $++^{*}$ & & 3 & Hypothetical / Unknown & 2 \\
\hline RSc2133 & 2.72 & 0.002 & nda & & $+*$ & & 2 & Hypothetical / Unknown & \\
\hline RSc2147 & 3.04 & 0.000 & 2.95 & 0.000 & $*$ & & 0 & Sorbitol dehydrogenase & \\
\hline RSc2359 & 4.01 & 0.000 & 3.95 & 0.000 & + & + & 3 & Hypothetical / Unknown & \\
\hline RSc2681 & 3.32 & 0.001 & 5.15 & 0.000 & + & & 0 & Transcription regulator (repressor, XRE family) & 0 \\
\hline RSe:2775 & 7.03 & 0.000 & 6.41 & 0.000 & 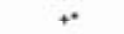 & + & 0 & HrpW family harpin & \\
\hline RSc2897 & 5.22 & 0.000 & 4.49 & 0.000 & + & & 2 & Hypothetical / Unknown & 1 \\
\hline RSC 3133 & 2.01 & 0.001 & 281 & 0.000 & $+*$ & & 0 & Acetyl transterase & \\
\hline RSc3155 & 3.34 & 0.000 & 4.17 & 0.000 & $+*$ & & 3 & Streptogramin lyase-related protein & 0 \\
\hline RSe3174 & nda & & 2.74 & 0.000 & + & + & 1 & Hypothetical / Unknown & \\
\hline RSc 3212 & 3.35 & 0.002 & 2.83 & 0.000 & + & + & 3 & TTSS-effector RipT & \\
\hline RSc 3272 & 270 & 0.000 & 2.47 & 0.000 & + & + & 0 & Hypothetical / Unknown & \\
\hline RSc 3290 & 4.05 & 0.000 & 4.32 & 0.000 & + & + & 0 & Hypothetical / Unknown & \\
\hline RSe 3369 & 2.28 & 0.002 & 2.63 & 0.000 & + & - & 3 & AvrPphE family protein & \\
\hline RSp 0028 & 273. & 0.001 & 1.09 & 0.004 & + & & 3 & LRR protein, GALA subfamiy & \\
\hline RSp0098 & 5.01 & 0.000 & 2.89 & 0.000 & in operon? & & 1 & Hypothetical / Unknown & \\
\hline RSp0099 & 4.53 & 0.000 & 306 & 0.000 & + & + & 3 & TTSS-effector RipA & \\
\hline RSp0160 & 3.62 & 0.000 & 4.13 & 0.000 & + & * & 2 & Hypothetical/Unknown & \\
\hline RSp0193 & nda & & 2.25 & 0.000 & + & + & 3 & PPR repeat containing protein & \\
\hline RSp0213 & 6.50 & 0.000 & 7.20 & 0.000 & + & + & 3 & Hypothetical / Unknown & \\
\hline RSp0215 & 1.80 & 0.000 & 3.53 & 0.000 & + & & 2 & Hypothetical / Unknown & \\
\hline RSp0218 & 272 & 0.007 & 4.68 & 0.000 & + & • & 3 & Hypothetical / Unknown & \\
\hline RSp0304 & 7.30 & 0.000 & 7.94 & 0.000 & + & - & 3 & AvrPphD tamily protein & \\
\hline RSp0323 & 2.47 & 0.000 & 3.52 & 0.000 & + & + & 1 & Hypothefical / Unknown & \\
\hline RSp0572 & 4.10 & 0.000 & 5.72 & 0.000 & + & + & 1 & Hypothetical / Unknown & \\
\hline RSp0693 & 7.98 & 0.000 & 7.44 & 0.000 & + & & 1 & Glyoxalase I (S-lactoylglutathione-lyase) & 1 \\
\hline RSp0694 & 6.81 & 0.000 & 6.90 & 0.000 & + & & 0 & Tryptophan-2,3-Dioxygenase & 1 \\
\hline RSp0695 & 6.37 & 0.000 & 5.69 & 0.000 & + & & 0 & Dehydrogenase & 2 \\
\hline RSp0696 & 7.32 & 0.000 & 6.34 & 0.000 & + & & 0 & Selenocysteine lyase & 2 \\
\hline RSp0697 & 6.97 & 0.000 & 7.20 & 0.000 & + & & 0 & Short chain dethydrogenase & 2 \\
\hline RSp 0698 & 5.62 & 0.000 & 6.25 & 0.000 & + & & 1 & Aspartatefyrosine/aromatic aminotransferase & 2 \\
\hline RSp0672 & 3.50 & 0.000 & 4.43 & 0.000 & + & + & 3 & LRR protein, GALA subfamily & \\
\hline RSp0731 & nda & & 235 & 0.000 & + & & 3 & Trehalose 6-phosphate synthase & \\
\hline RSp0732 & 5.90 & 0.000 & 6.74 & 0.000 & + & + & 3 & Hypothetical / Unknown & \\
\hline RSp0822 & 2.15 & 0.013 & 3.61 & 0.000 & + & & 2 & AvrPphF family protein & \\
\hline RSp0837 & 270 & 0.000 & 1.00 & 0.000 & $+*$ & & 3 & Hypothetical / Unknown & \\
\hline RSp0839 & 4.87 & 0.000 & 5.74 & 0.000 & + & + & 1 & Hip Yorelated protein & \\
\hline RSp0840 & 1.35 & 0.020 & 220 & 0.000 & in operon? & & 0 & Methyl-accepting chemotaxis transducer protein & 2 \\
\hline RSp0841 & 7.08 & 0.000 & 7.19 & 0.000 & * & + & 1 & Lyzozyme-related tranglycosylase & \\
\hline
\end{tabular}

Continued on next page

${ }^{\mathrm{a}}$ Definition of the different classes is based on regulation pattern and presence or absence of an $h r p_{I I}$ box in gene promoters.

${ }^{\mathrm{b}}$ For each gene and for each experimental condition the ratio (expressed as a $\log _{2}$ value) of transcription in the $h r p B$-expressing strain versus the $h r p B$ deficient mutant is given together with the corresponding $p$ value of the Student $t$-test. Data with absolute values $>2$ and $p$ values $<0.01$ are highlighted in dark colors (orange for $h r p B$ up-regulated gene, blue for $h r p B$ down-regulated genes). Data highlighted with light colors either have an absolute value of the ratio between 1 and 2 or have a $p$ value between 0.01 and 0.05 . A few additional genes showing a low threshold value in the two assay conditions have been included in the table when they form part of an operon that includes other $h r p B$-regulated genes.

"The presence of a $h r p_{I I}$-box in the gene promoter is indicated by "+" for a canonical motif (9), by "+*" when a singlel mismatch is present relative to the consensus, "in operon?" indicates that this gene could be part of an operon that harbors a hrp II box in its promoter. A border highlights the corresponding operons and the names of the corresponding genes are shown in bold.

${ }^{\mathrm{d}}+$ indicates previously identified $\operatorname{brg}$ genes.

${ }^{\mathrm{e}} \mathrm{N}$-terminal Type III export signals. This column shows the numbers of the following rules that are fulfilled by protein $\mathrm{N}$-terminus relative to the amino acid bias found for type III secretion system (TTSS)-secreted proteins: i) high content in serine and proline residues ( $>18 \%)$, ii) low content in leucine residues $(<6 \%)$, and iii) absence of acidic residues in the first 12 amino acids. hrp means that the corresponding genes are part of the $h r p$ gene cluster that encodes the TTSS.

${ }^{\mathrm{f}}$ An updated annotation is available on our annotation webpage.

${ }^{g}$ Results of the semiquantitative reverse transcription-polymerase chain reaction (RT-PCR). 2 indicates a qualitative difference was observed (amplified fragment missing in one condition), 1 that difference in band intensity was observed, and 0 indicates same intensity for the band in the three strains. 
Table 1. Continued from preceding page

\begin{tabular}{|c|c|c|c|c|c|c|c|c|c|}
\hline Gene ID & $\begin{array}{l}1000 / 1525 \\
\text { ratio }\end{array}$ & $\begin{array}{c}\text { P- } \\
\text { value }\end{array}$ & $\begin{array}{c}\text { pam5/1525 } \\
\text { ratio }\end{array}$ & $\begin{array}{c}\mathrm{P}- \\
\text { value }\end{array}$ & $\begin{array}{c}\operatorname{hrp}_{I I} \\
\text { box }\end{array}$ & brg genes & $\begin{array}{c}\text { Export } \\
\text { signal }\end{array}$ & $\begin{array}{l}\text { Corresponding protein or } \\
\text { predicted function }\end{array}$ & $\begin{array}{c}\text { RT-PCR } \\
\text { validation }\end{array}$ \\
\hline & \multicolumn{9}{|c|}{ Class I continued } \\
\hline RSp0842 & 3.98 & 0.000 & 4.11 & 0.000 & . & . & 3 & LRR protein, PopC subtamily & \\
\hline RSp0845 & 3.07 & 0.001 & 5.93 & 0.000 & + & + & 3 & Hypothetical / Unknown & \\
\hline RSp0848 & 4.65 & 0.000 & 5.63 & 0.000 & - & - & 0 & Hypothetical / Unknown & \\
\hline RSp0853 & 5.53 & 0.009 & 6.91 & 0.000 & + & + & $\mathrm{nrp}$ & Нрав & \\
\hline RSp0354 & 7.19 & 0.000 & 7.55 & 0.000 & + & + & hrp & $\mathrm{HepZ}$ & \\
\hline RSposss & 7609 & 0.030 & 7.21 & 0.001 & + & + & hrp & HipY & \\
\hline RSp0856 & 6.67 & 0.000 & 834 & 0.000 & + & + & hrp & $\operatorname{HipX}$ & \\
\hline RSp0857 & 4.34 & 0,000 & 5.71 & 0.000 & + & + & hrp & Hipw & \\
\hline RSp0858 & 4.45 & 0.000 & 4.08 & 0.000 & + & + & hrp & Hopv & \\
\hline RSp0859 & 7.07 & 0.000 & 7.62 & 0.000 & 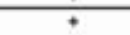 & + & $\mathrm{hrp}$ & Hires & \\
\hline RSp0860 & 6.14 & 0.330 & 7.89 & 0.000 & + & + & hip & HecR & \\
\hline RSp0862 & 5.45 & 0.001 & 5.58 & 0.000 & + & + & hrp & HpaP & \\
\hline RSp0s63 & 2.55 & 0.000 & 3.43 & 0.000 & + & + & hip & HerV & \\
\hline RSp0865 & 8.36 & 0.000 & 8.35 & 0.000 & + & + & hrp & Hipk & \\
\hline RSp0s66 & 7.61 & 0.000 & 8.00 & 0.000 & + & + & hrp & Hips & \\
\hline RSp0867 & 4.76 & 0.000 & 6.09 & 0.000 & • & - & hrp & Hew & \\
\hline RSp0868 & 6.64 & 0.000 & 7,37 & 0.000 & + & + & hrp & $\mathrm{HrpH}$ & \\
\hline RSp0869 & 5.43 & 0.000 & 6.28 & 0.000 & . & + & hrp & HipF & \\
\hline RSp0870 & 3.98 & 0.000 & 4.60 & 0.000 & + & + & hrp & Hran & \\
\hline RSp0871 & 5.71 & 0.000 & 6.03 & 0.000 & + & + & hrp & HipD & \\
\hline RSp0:72 & 4.02 & 0.004 & 5.80 & 0.000 & + & + & hip & HreT & \\
\hline RSp0875 & 5.69 & 0.000 & 5.59 & 0.000 & $\cdot$ & * & 3 & PopC & \\
\hline RSp0s76 & 8.93 & 0.000 & 8.89 & 0.000 & + & + & 3 & PopB & \\
\hline RSp0877 & 8.95 & 0.000 & 8.14 & 0.000 & + & + & 2 & PopA & \\
\hline RSp0879 & 1.79 & 0.029 & 3.20 & 0.000 & + & + & 3 & Hypothetical/ Unknown & \\
\hline RSpo8s2 & 5.23 & 0.000 & 6.16 & 0.000 & + & & 0 & Hypothetical / Unknown & 2 \\
\hline RSposss & 1.42 & 0.083 & 2.06 & 0.002 & + & + & 1 & Hypothetical / Unknown & \\
\hline RSp0900 & 6.68 & 0.000 & 6.82 & 0.000 & + & & 3 & POpF2 & \\
\hline RSp1022 & 5.12 & 0.000 & 6.10 & 0.000 & + & + & 2 & Hypothetical / Unknown & \\
\hline RSp1031 & 1.94 & 0.007 & 3.50 & 0.000 & - & + & 3 & Hypothetical / Unknown & \\
\hline RSp1130 & 2.38 & 0.001 & 5.24 & 0.000 & + & . & 3 & Hypothetical / Unknown & \\
\hline RSp1212 & 6.40 & 0.001 & 4.86 & 0.000 & + & & 3 & Hypothetical / Unknown & 1 \\
\hline RSp1236 & 2.70 & 0.003 & 4.33 & 0.000 & $+*$ & & 3 & Hypothetical / Unknown & \\
\hline RSp1239 & 3.70 & 0.000 & 6.12 & 0.000 & $*$ & & 3 & Hypothetical / Unknown & 2 \\
\hline RSp1240 & 201 & 0.000 & 3.99 & 0.000 & $+*$ & & 2 & Transplycosylase & \\
\hline RSp1277 & 2.57 & 0.000 & 4.30 & 0.000 & + & & 2 & Hypothetical / Unknown & 2 \\
\hline RSp1281 & 1.46 & 0.016 & 4.27 & 0.000 & + & + & 3 & Hypothetical / Unknown & \\
\hline RSp1461 & 3.74 & 0.000 & 5.07 & 0.000 & • & & 2 & Conserved hypothetical protein & \\
\hline RSp1462 & 1.66 & 0.000 & 2.30 & 0.000 & in operon? & & 0 & Outer membrane effux protein & \\
\hline RSp1463 & 206 & 0.005 & 2.88 & 0.000 & in operon? & & 0 & ABC transporter, permease component & 0 \\
\hline RSp1474 & 4.48 & 0.002 & 3.28 & 0.000 & + & & 0 & Hypothetical / Unknown & 1 \\
\hline RSp1475 & 3.83 & 0.000 & 5.09 & 0.000 & + & & 3 & Hypothetical / Unknown & 2 \\
\hline RSp1555 & 8.74 & 0.000 & 7.61 & 0.000 & + & & $\frac{2}{3}$ & PopF1 & \\
\hline RSp1582 & 4.16 & 0.004 & 4.23 & 0.000 & $4^{*}$ & & 3 & Hypothetical / Unknown & \\
\hline \multicolumn{10}{|c|}{ Class II } \\
\hline$\overline{R S 00096}$ & 2.44 & 0.000 & 3.20 & 0.000 & & & 0 & Hypothetical / Unknown & \\
\hline RSc0257 & 4.07 & 0.000 & 6.58 & 0.000 & & + & 2 & Ankyrin Repeat harboring protein & \\
\hline RSC0321 & 2.23 & 0.003 & 3.22 & 0.000 & & & 3 & Hypothetical / Unknown & 1 \\
\hline RSC0893 & 1.35 & 0.003 & 3.00 & 0.000 & & & 0 & Transposase & \\
\hline RSc1083 & 2.07 & 0.000 & 1.71 & 0.000 & & & 0 & Aldose 1-epimerase & \\
\hline RSc1344 & 1.18 & 0.002 & 2.23 & 0.000 & & & 1 & Esterase & \\
\hline RSc1517 & 1.97 & 0.000 & 2.62 & 0.001 & & & 3 & Hypothetical / Unknown & \\
\hline RSc1723 & 4.69 & 0.001 & 5.19 & 0.000 & & & 3 & Hypothetical / Unknown & \\
\hline RSc1815 & 3.93 & 0.000 & 5.24 & 0.000 & & + & 1 & Av8Bs 3 family protein & \\
\hline RSc1841 & 1.80 & 0.014 & 2.33 & 0.000 & & & 0 & Hydrolase & \\
\hline RSc1900 & 4.07 & 0.008 & nda & & & & 0 & Hypothetical / Unknown & \\
\hline RSc1901 & 2.01 & 0.001 & 1.53 & 0.000 & & & 1 & Hypothetical / Unknown & \\
\hline RSc2109 & 2,30 & 0.001 & 1.98 & 0.001 & & & 1 & Hypothetical / Unknown & \\
\hline RSc2113 & 2.01 & 0.001 & nda & & & & 1 & Oxdoreductase & \\
\hline RSC2200 & 1.95 & 0.000 & 2.19 & 0.000 & & & 3 & $A B C$ transporter & \\
\hline RSc2291 & 2.30 & 0.000 & nda & & & & 2 & Lysozyme-related transglycosylase & \\
\hline RSc2376 & 2.94 & 0.000 & 2.62 & 0.000 & & & 0 & 4Fo-4S binding electron transporter & \\
\hline RSc3162 & 2.41 & 0.004 & 1.68 & 0.004 & & & 1 & Autotransported hemagglutinin-related protein & \\
\hline RSp0093 & 2.62 & 0.006 & 3.45 & 0.000 & & & 1 & TIS1421-transposase & \\
\hline RSp0159 & 3.70 & 0.003 & 4.47 & 0.000 & & & 0 & Hypothetical / Unknown & \\
\hline RSp0216 & 4.03 & 0.000 & 4.96 & 0.000 & & & 3 & Serinerthreonine-protein kinase & \\
\hline RSp0286 & 2.83 & 0.005 & 3.28 & 0.000 & & & 3 & Hemin-binding-related protein & \\
\hline RSp0s87 & 2.52 & 0.044 & 3.95 & 0.000 & & & 1 & Conserved hypothetical protein & \\
\hline RSp0825 & 5.09 & 0.000 & 5.76 & 0.000 & & & 1 & Spermidine synthase & 1 \\
\hline RSp0834 & nda & & 2.04 & 0.000 & & & 0 & Hexuronate transporter & \\
\hline RSpo852 & 1.19 & 0.008 & 2.26 & 0.000 & & & hip & HipG & \\
\hline RSp0873 & 5.10 & 0.000 & 7.09 & 0.000 & & • & hrp & Hrps & \\
\hline RSp0888 & 1.41 & 0.000 & 223 & 0.000 & & & 0 & Glyoxatase & \\
\hline RSp0943 & 1.25 & 0.021 & 3.09 & 0.002 & & & 3 & Aspartate aminotransferase & \\
\hline RSp1150 & nda & & 2.41 & 0.000 & & & 1 & Hypothetical / Unknown & \\
\hline RSp1270 & 3.05 & 0.000 & 4.87 & 0.000 & & & 0 & Hypothetical / Unknown & \\
\hline RSp1280 & nda & & 3.82 & 0.000 & & & 0 & Carbohydrate kinase & \\
\hline
\end{tabular}


conducted on a subset of these genes in order to confirm these observations. These genes included RSp0788, a hrpBrepressed gene that encodes a predicted carbamoyl transferase, RSp0840, a Class I gene that encodes a chemotaxy-related protein, and RSp693 and Rsp698, two Class I genes from a single operon and encoding predicted intracellular enzymes. Rsp0877 that encodes the PopA protein (Arlat et al. 1994) was also included as a $h r p B$-regulated control, as well as $16 \mathrm{~S}$ rDNA and RSc2690 (oxyR) as constitutive controls, since these two genes behaved as constitutively expressed, based on microarray analysis. These experiments were conducted on the two mRNA populations used for microarray analysis. Data shown in Figure 2 are the average of the two experiments. They confirm that $h r p B$ can act as a negative regulator and that the $h r p B$ regulon extends beyond TTSS-related functions.

\section{Biological functions encoded by $h r p B$-regulated genes.}

TTSS and TTSS effectors. Apart from the components of the type III secretion machinery and the previously identified candidate effectors, 26 new $h r p B$-activated genes are predicted to encode probable TTSS substrates, since the composition of their first $50 \mathrm{~N}$-terminal amino acid domain complies with at least two of the three rules previously defined for $R$. solanacearum TTSS effectors: i) high content in serine and proline residues

Table 1. Continued from preceding page

\begin{tabular}{|c|c|c|c|c|c|c|c|c|c|}
\hline Gene ID & $\begin{array}{l}1000 / 1525 \\
\text { ratio }\end{array}$ & $\begin{array}{c}\text { P- } \\
\text { value }\end{array}$ & $\begin{array}{c}\text { pam5/1525 } \\
\text { ratio }\end{array}$ & $\begin{array}{c}\text { P- } \\
\text { value }\end{array}$ & $\begin{array}{l}\operatorname{hrp}_{I I} \\
\text { box }\end{array}$ & brg genes & $\begin{array}{l}\text { Export } \\
\text { signal }\end{array}$ & $\begin{array}{l}\text { Corresponding protein or } \\
\text { predicted function }\end{array}$ & $\begin{array}{c}\text { RT-PCR } \\
\text { validation }\end{array}$ \\
\hline & \multicolumn{9}{|c|}{ Class II continued } \\
\hline RSp1386 & 2.39 & 0.000 & 2.47 & 0.000 & & & 0 & Hypothetical / Unknown & \\
\hline RSp1391 & nda & & 2.61 & 0.000 & & & 0 & Flagellar protein & \\
\hline RSp1440 & nda & & 2.94 & 0.001 & & & 1 & Hypothetical / Unknown & \\
\hline RSp1460 & 2.71 & 0.006 & 4.14 & 0.000 & & + & 3 & Hypothetical / Unknown & \\
\hline RSp1466 & 4.91 & 0.000 & 5.32 & 0.000 & & & 1 & Hypothetical / Unknown & 2 \\
\hline RSp1467 & 4.32 & 0.001 & 5.05 & 0.000 & & & 1 & Hypothetical/Unknown & 2 \\
\hline RSp1536 & 3.06 & 0.000 & 2.34 & 0.000 & & & 2 & Hemagglutinin-related protein & \\
\hline RSp1581 & nda & & 2.27 & 0.000 & & & 1 & Hydroperoxidase HPII & \\
\hline \multicolumn{10}{|c|}{ Class III } \\
\hline RSc0447 & -1.61 & 0.162 & -2.70 & 0.000 & & & 0 & Hypothetical / Unknown & \\
\hline RSc0594 & 1.18 & 0.304 & -3.19 & 0.000 & & & 0 & Transmembrane protein & \\
\hline RSc0595 & $=0.16$ & 0.799 & -2.11 & 0.000 & & & 1 & Outer membrane TonB-dependent receptor protein & \\
\hline RSc1810 & 0.95 & 0.197 & -2.47 & 0.000 & & & 0 & Beta-ketoacyl synthase & \\
\hline RSc1811 & 1.08 & 0.016 & -2.50 & 0.000 & & & 0 & Siderophore synthase & \\
\hline RSc1s12 & 1.06 & 0.055 & -3.62 & 0.000 & & & 1 & Hypothetical / Unknown & \\
\hline RSe1813 & 0.97 & 0.010 & -2.02 & 0.000 & & & 0 & Transcription activator (AraC family) & \\
\hline RSc1892 & -0.93 & 0.000 & -2.89 & 0.000 & & & 0 & Two component response regulator & 1 \\
\hline RSc1918 & nda & & -2.36 & 0.000 & & & 0 & Bacteriophage tail protein & \\
\hline RSc1938 & nda & & -2.57 & 0.000 & & & 1 & Bacteriophage capside scatolding protein & \\
\hline RSc1942 & -0.48 & 0.297 & -2.08 & 0.000 & & & 1 & Hypothetical / Uniknown & \\
\hline RSc1943 & -0.21 & 0.681 & -2.26 & 0.000 & & & 1 & Hypothetical / Unknown & \\
\hline RSC2208 & nda & & -2.18 & 0.000 & & & 0 & Pirin-related protein & \\
\hline RSe2374 & $=0.77$ & 0.098 & -2.69 & 0.000 & & & 1 & Hypothetical / Unknown & \\
\hline RSC2689 & -1.23 & 0.232 & -2.47 & 0.000 & & & 1 & Hypothetical / Unknown & \\
\hline RSC3092 & nda & & -2.61 & 0.000 & & & 1 & Hypothetical / Unknown & \\
\hline RSc3219 & 0.54 & 0.165 & -2.08 & 0.000 & & & 0 & Hypothetical / Unknown & \\
\hline RSc3220 & nda & & -2.20 & 0.000 & & & 1 & VGR-related protein & \\
\hline RSc3222 & -0.11 & 0.877 & -2.35 & 0.000 & & & 0 & Probable pseudogene & \\
\hline RSe3248 & -0.28 & 0.818 & -2.02 & 0.000 & & & 0 & Bacteriophage protein & \\
\hline RSC3378 & -0.29 & 0.599 & -2.03 & 0.000 & & & 0 & Phosphatidylserine-synthase related protein & \\
\hline RSp0081 & -0.60 & 0.028 & -2.21 & 0.000 & & & 0 & Hypothetical / Unknown & \\
\hline RSp0100 & -0.80 & 0.026 & -2.38 & 0.000 & & & 1 & TonB-dependent receptor & \\
\hline RSp02S8 & nda & & -3.16 & 0.000 & & & 1 & Transcription regulator (repressor PadR famli) & \\
\hline RSp0413 & 0.14 & 0.544 & -2.78 & 0.000 & & & $\overline{0}$ & Conserved hypothetical protein & \\
\hline RSp0414 & -0.05 & 0.804 & -2.44 & 0.000 & & & 2 & TonB-dependent receptor & \\
\hline RSp0417 & -0.25 & 0.473 & -3.64 & 0.000 & & & 0 & O-Acetyl serine sulfhydrase & \\
\hline RSp0418 & -0.23 & 0.402 & -3.87 & 0.000 & & & 0 & Omithine cyclodeaminase & 2 \\
\hline RSp0419 & -0.54 & 0.042 & -2.86 & 0.000 & & & 0 & Siderophore synthetase component & \\
\hline RSp0420 & -0.12 & 0.513 & -3.68 & 0.000 & & & 0 & Transporter & \\
\hline RSp0421 & $=0.47$ & 0.192 & -3.39 & 0.000 & & & 0 & Siderophore synthetase component & \\
\hline RSp0422 & -0.14 & 0.496 & -3.96 & 0.000 & & & 0 & Siderophore synthetase component & 2 \\
\hline RSp0423 & 0.04 & 0.900 & -3.63 & 0.000 & & & 0 & Aldolase & \\
\hline RSp0424 & -0.44 & 0.208 & -3.87 & 0.000 & & & 0 & Staphyloferrin B siderophore decarboxylase & \\
\hline RSp0532 & -2.25 & 0.017 & -3.36 & 0.000 & & & 0 & Aminopeptidase & \\
\hline RSp0779 & -1.52 & 0.063 & -2.10 & 0.000 & & & 0 & Acyl homoserine lactone synthase & 1 \\
\hline RSp0780 & $-1,80$ & 0.015 & -2.29 & 0.000 & & & 1 & Hypothetical/ Partial homology & \\
\hline RSp0781 & $-2,42$ & 0.032 & -1.92 & 0.000 & & & 0 & Cystathionine gamma-synthase & \\
\hline RSp0782 & -2.65 & 0.021 & -2.19 & 0.000 & & & 1 & Aminoacyl-tRNA symthetase-related protein & \\
\hline R5p0783 & -2.09 & 0.049 & -1.81 & 0.001 & & & 0 & Acyl carier protein & \\
\hline RSp0784 & $-2,58$ & 0.022 & -2.36 & 0.000 & & & 0 & Fatty acid desaturase & \\
\hline RSp078s & -2.09 & 0.010 & -1.68 & 0.000 & & & 0 & Hypothetical / Unknown & \\
\hline RSp0786 & -2.26 & 0.015 & -2.02 & 0.000 & & & 0 & 3-oxoacyl-facyl-camier-protein] synthase & \\
\hline RSp0787 & -2.51 & 0.017 & -2.24 & 0.000 & & & 0 & Acyl-COA synthetase & \\
\hline RSp0788 & -2.44 & 0.017 & -2.42 & 0.000 & & & 1 & Carbamoyl transferase & \\
\hline RSp0789 & -2.25 & 0.018 & -1.27 & 0.002 & & & 0 & Hypothetical / Partial homology & \\
\hline RSp0790 & -2.00 & 0.037 & -2.27 & 0.000 & & & 1 & Hydrolase & \\
\hline RSp0792 & -2.69 & 0.029 & -2.49 & 0.001 & & & 0 & Fatty acid desaturase & 1 \\
\hline RSp1377 & -0.14 & 0.365 & -2.23 & 0.000 & & & 0 & Transcription regulator (AsnC family) & \\
\hline RSp1378 & -0.84 & 0.058 & -2.33 & 0.000 & & & 0 & Transposase remnant & \\
\hline \multicolumn{10}{|c|}{ Class IV } \\
\hline RSC1804 & 2.90 & 0.010 & -205 & 0.000 & & & 0 & Non-rbosomic peptide synthase & \\
\hline RSc1805 & 2.81 & 0.015 & -206 & 0.000 & & & 0 & Sidereophore-like synthase & \\
\hline RSc1807 & 2.17 & 0.013 & -1.11 & 0.000 & & & 0 & TonB-dependent siderophore receptor & $2^{*}$ \\
\hline RSc1808 & 2.26 & 0.039 & -1.30 & 0.005 & & & 0 & ABC transporter & \\
\hline
\end{tabular}


$(\geq 18 \%)$, ii) low content in leucine residues $(\leq 6 \%)$, and iii) absence of acidic residues in the first 12 amino acids (Cunnac et al. 2004b). In addition, 18 of 26 of these candidates contain at least one basic amino acid within the seven first residues, another general feature of $R$. solanacearum effectors (Cunnac et al. $2004 \mathrm{~b}$ ). Among these 26 new predicted proteins are some homologs of known TTSS effectors from $R$. solanacearum
(RSp0028, RSp0215) or from other plant pathogens (RSp0822, RSp1239, RSp1277). A large proportion of these candidate effector genes (20 of 26) have no counterpart in the nonpathogenic and taxonomically close species Ralstonia metallidurans (Table $3)$. Among these novel candidate effectors are several proteins with possible enzymatic activity, including RSp0216, a putative protein kinase that is best related to eukaryotic serine/threonine

Table 2. Validation of $h r p B$-regulated genes through gene fusions ${ }^{\mathrm{a}}$

\begin{tabular}{|c|c|c|c|c|}
\hline \multirow[b]{2}{*}{ Ralstonia solanacearum gene } & \multicolumn{3}{|c|}{$\beta$-galactosidase activity (Miller's units) } & \multirow{2}{*}{$\begin{array}{c}\text { Induction ratio } \\
\text { wt/hrpB } B^{-} \text {or pAM5/hrpB }\end{array}$} \\
\hline & Wild-type & hrpB $B^{-}$ & +pAM5 & \\
\hline RSp1212 & $56(5)$ & $12(1.4)$ & ND & 4.7 \\
\hline RSp1236 & $30.7(1.5)$ & $11.5(0.4)$ & $114(5)$ & 9.9 \\
\hline RSp1461 & $59(5.7)$ & $11.8(1.0)$ & ND & 5.0 \\
\hline RSp1475 & $5.6(0.2)$ & $3.2(0.3)$ & $30.6(5.4)$ & 9.6 \\
\hline RSp1582 & $19.8(1.2)$ & $9.8(0.2)$ & $71(2.5)$ & 7.2 \\
\hline RSc0041 & $29.4(1.4)$ & $10.1(2.0)$ & $51.9(1.5)$ & 5.1 \\
\hline $\mathrm{RSc} 2101$ & $21(2)$ & $13.5(1)$ & $89(6)$ & 6.6 \\
\hline
\end{tabular}

${ }^{a} \beta$-galactosidase activity of strains carrying pCZ367 fusions in different GMI1000 genes and effect of $h r p B$ disruption ( $\left.h r p \boldsymbol{B}^{-}\right)$or overexpression (+ pAM5). Assays were performed on bacteria grown in $h r p$-inducing minimal medium. Values in brackets are standard variations. ND $=$ not done.

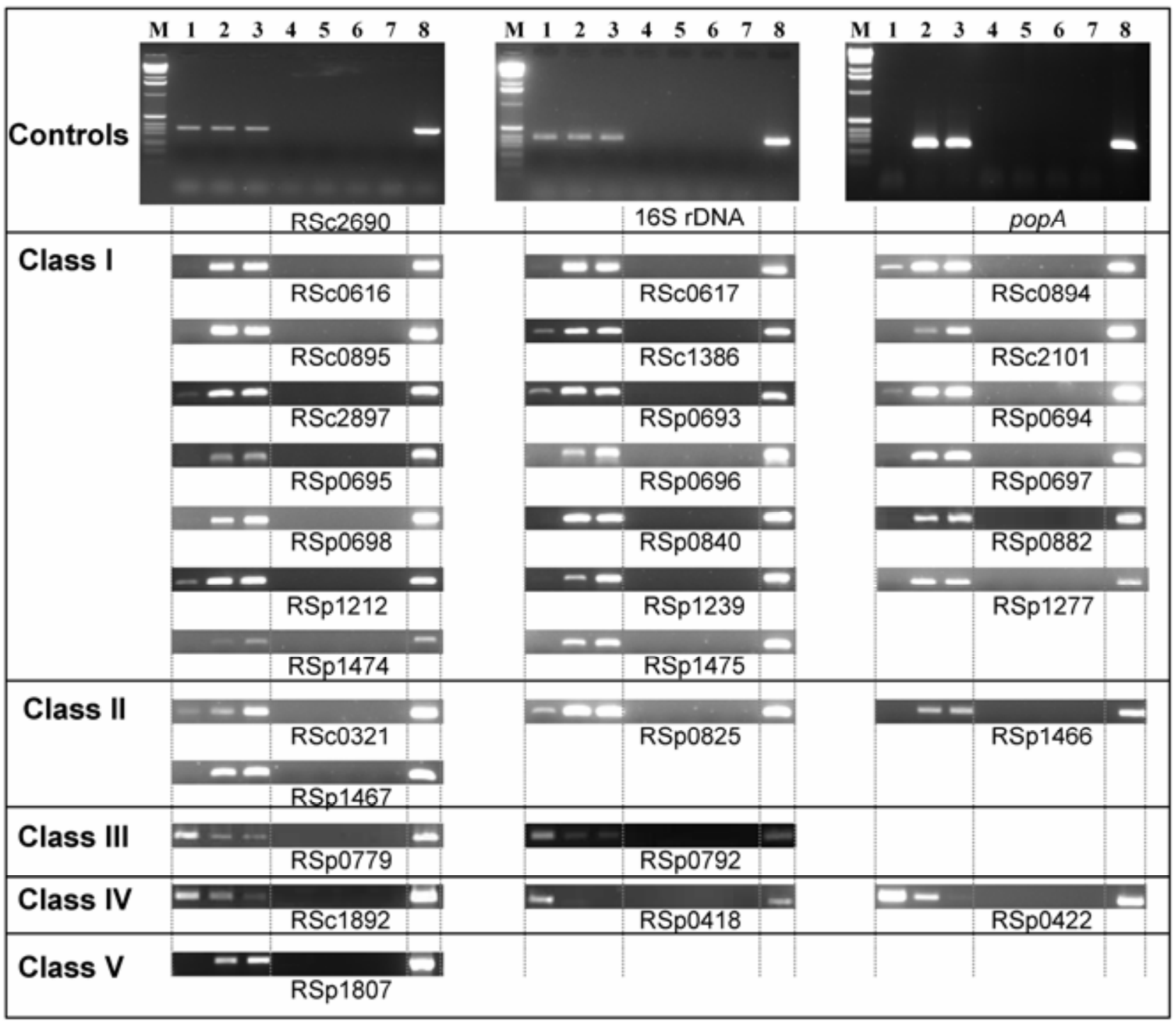

Fig. 1. Semiquantitative reverse transcriptase-polymerase chain reaction (RT-PCR) analysis of selected hrpB-regulated genes of Ralstonia solanacearum. Full gels are only shown for the controls; only the part of the gel showing the appropriate amplicon is shown for the other samples. M = DNA size marker. Lanes 1 and 4, hrpB-deficient mutant GMI1525; lanes 2 and 5, GMI1000; lanes 3 and 6, GMI1728; lane 7, water control; lane 8, GMI1000 genomic DNA control. Lanes 4, 5, and 6 correspond to control RNA sample (without reverse transcriptase). Controls include two constitutive genes (RSc2690, 16S rDNA) and the $h r p B$-regulated $p o p A$ gene. 
protein kinases, RSc3155, a probable hydrolase, and RSc2291 and RSp1240, which are both related to lysozyme transglycosylases. Another protein encoded by a Class I gene (Rsp0841) and harboring a signal peptide for the general secretion pathway is also predicted to have transglycosylase function, suggesting that it could play a role in remodeling peptidoglycan during the positioning of the TTSS into the cell envelope.

Metabolic functions. Several hrpB-regulated genes encode enzymes most probably involved in intermediate metabolism (such as RSc2147, coding for a predicted intracellular sorbitol-

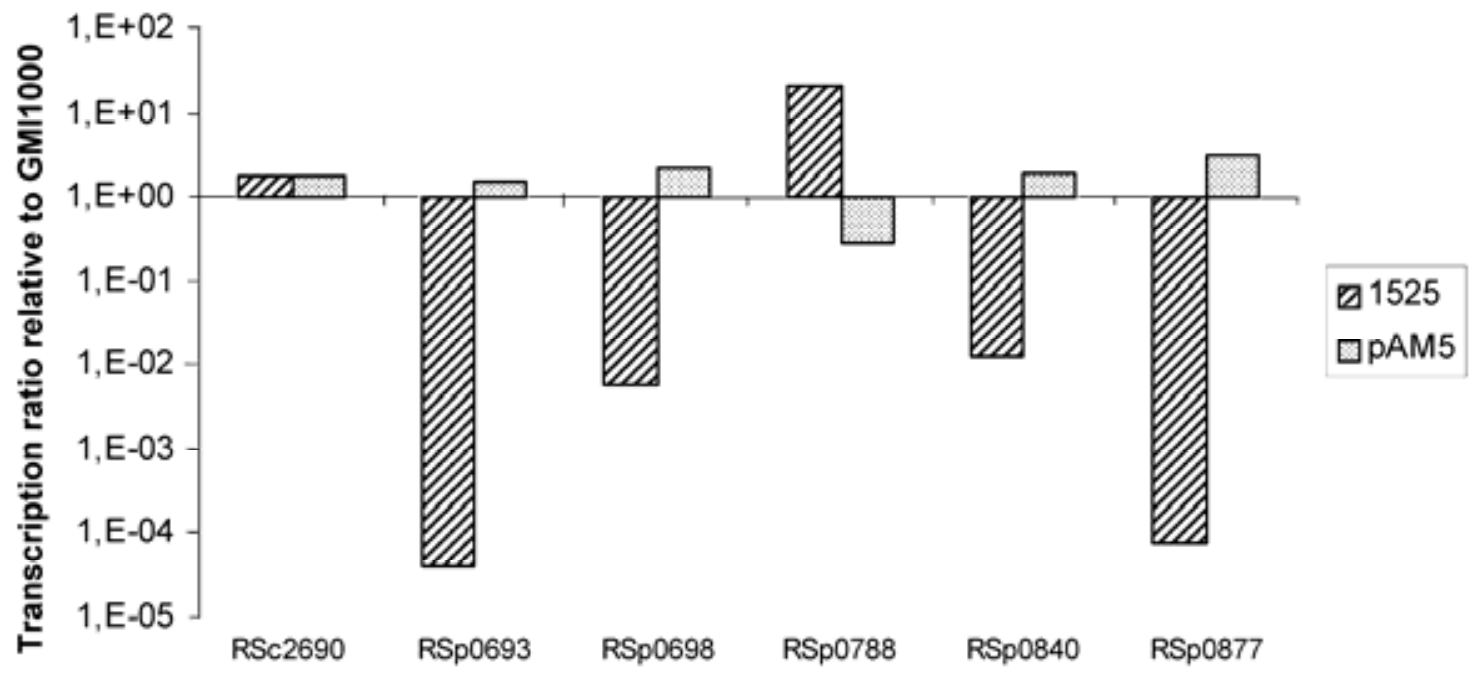

Fig. 2. Validation of non-type III secretion system-related $h r p B$-regulated genes by reverse transcriptase-polymerase chain reaction (RT-PCR). Expression of different genes in the $h r p B$-deficient mutant GMI1525 (hatched boxes) and in strain GMI1728 overexpressing $h r p B$ (dotted boxes), compared with their expression in the wild-type strain GMI1000 by real time RT-PCR. The data are presented on a log scale and correspond to the ratio of the amount of mRNA present in the tested strains relative to the reference strain GMI1000.

Table 3. The 26 novel candidate type III secretion system (TTSS)-effectors identified in this study ${ }^{\mathrm{a}}$

\begin{tabular}{|c|c|c|c|c|c|c|}
\hline \multirow[b]{2}{*}{ Gene } & \multirow[b]{2}{*}{ Class } & \multirow[b]{2}{*}{ Location } & \multicolumn{2}{|r|}{ Gene product features } & \multirow[b]{2}{*}{$\mathrm{CH}_{4}^{\mathrm{b}}$} & \multirow[b]{2}{*}{$\% \mathbf{G C}$} \\
\hline & & & Size (aa) & Description & & \\
\hline RSc0041 & I & & 430 & No homology & - & \\
\hline $\mathrm{RSc} 0321$ & II & & 642 & Partial homology to RSc2132 (E = 1e-08) & _- & \\
\hline RSc1517 & II & & 58 & No homology & - & \\
\hline RSc1723 & II & & 147 & No homology, putative nuclear localization signals & _ & 49.4 \\
\hline RSc2101 & I & & 334 & No homology & - & \\
\hline $\mathrm{RSc} 2133$ & I & ACUR $^{\mathrm{d}}$ & 90 & Partial homology to RSc3065 (E = 3e-19) & - & \\
\hline RSc2291 & II & & 198 & Homology to Pseudomonas putida $\mathrm{PP} 3422(\mathrm{E}=4 \mathrm{e}-33)$ & $E=2 e-51$ & \\
\hline RSc2897 & I & & 122 & Global homology to $R$. solanacearum FliT $(\mathrm{E}=2 \mathrm{e}-24)$ & $\mathrm{E}=1.5 \mathrm{e}-09$ & \\
\hline RSc3155 & I & & 451 & Hydrolase; homology to Staphylococcus aureus Vgb $(\mathrm{E}=8 \mathrm{e}-21)$ & - & \\
\hline RSp0028 & I & & 603 & Leucine-rich repeat protein GALA3 & _ & \\
\hline RSp0215 & I & ACUR border & 754 & $\begin{array}{l}\text { HLK family; homology to Xanthomonas campestris pv. campestris XCC1247 } \\
(\mathrm{E}=\mathrm{e}-43)\end{array}$ & - & \\
\hline RSp0216 & II & ACUR & 577 & Serine/threonine protein kinase; homology to Yeast YKL101W (E = 8e-14) & _ & 52.4 \\
\hline RSp0286 & II & & 816 & $\begin{array}{l}\text { Hemin-binding outer-membrane protein; homology to Bordetella } \\
\text { bronchiseptica BB1769 }(\mathrm{E}=\mathrm{e}-149)\end{array}$ & - & \\
\hline RSp0731 & I & & 557 & Alpha,alpha-trehalose-phosphate synthase; homology to RSp1105 (E = e-103) & $\mathrm{E}=7 \mathrm{e}-117$ & \\
\hline RSp0822 & I & & 350 & Homology to $P$. syringae pv. tomato type III effector $\operatorname{HopPtoF}(\mathrm{E}=5 \mathrm{e}-18)$ & - & \\
\hline RSp0837 & I & $\begin{array}{l}\text { hrp } \text { cluster } \\
\text { border }\end{array}$ & 182 & No homology & - & \\
\hline RSp0943 & II & & 402 & $\begin{array}{l}\text { Aspartate aminotransferase; homology to P. syringae pv. tomato PSPTO2925 } \\
(\mathrm{E}=\mathrm{e}-164)\end{array}$ & $E=4 e-46$ & \\
\hline RSp1212 & I & & 296 & No homology & _- & 61.9 \\
\hline RSp1236 & I & & 605 & Partial homology to RSp1475 (E=e-110) & - & \\
\hline RSp1239 & I & & 943 & $\begin{array}{l}\text { Partial homology to X. campestris pv. vesicatoria type III effector XopC } \\
(\mathrm{E}=2 \mathrm{e}-81)\end{array}$ & - & \\
\hline RSp1240 & I & & 427 & Transglycosylase; homology to X. axonopodis pv. citri XACb0007 (E = e-128) & $\mathrm{E}=1.6 \mathrm{e}-14$ & \\
\hline RSp1277 & I & & 518 & Homology to $P$. syringae pv. tomato type III effector HopPtoA1 $(\mathrm{E}=\mathrm{e}-33)$ & - & \\
\hline RSp1461 & I & & 105 & Homology to RSc3204 (E = 6e-16) & - & \\
\hline RSp1475 & I & & 448 & Homology to RSp1236 (E = e-123) & _ & \\
\hline RSp1536 & I & & 846 & $\begin{array}{l}\text { Hemagglutinin-related protein; homology to } X \text {. campestris pv. campestris } \\
\text { XCC1794 }(\mathrm{E}=3 \mathrm{e}-31)\end{array}$ & $\mathrm{E}=4.1 \mathrm{e}-20$ & \\
\hline RSp1582 & II & & 277 & No homology & - & 59.2 \\
\hline
\end{tabular}

${ }^{a}$ Analysis of the N-terminal regions (50 first amino acids) of gene products from Classes I and II indicated that the genes listed in this table encode proteins that display compositional biases in their N-terminal region that are similar to known GMI1000 TTSS-effectors (Cunnac et al. 2004b).

${ }^{\mathrm{b}}$ The detection of a homologous sequence in the non pathogenic Ralstonia metallidurans $\mathrm{CH} 34$ is indicated by the E Blast score.

${ }^{\mathrm{c}}$ The GC content of the gene is indicated when significantly different from the mean of the GMI1000 genome (67\%).

${ }^{\mathrm{d}}$ ACUR $=$ Alternate codon usage region (Salanoubat et al. 2002). 
dehydrogenase, RSc3133, coding for an acetyl-transferase, or the RSc1841, RSc2113, and RSp1280 genes [Table 1]). Another example concerns two genes (RSp0888, RSp0893) involved in the degradation of cumate and RSp0834 (exuT), a gene involved in the uptake of galacturonic acid, the main degradation product of pectin (Gonzales and Allen 2003). An illustration of functions probably independent of Type III secretion concerns an operon of six genes (RSp0693 through RSp0698) that encodes enzymes putatively involved in the bioconversion of a tryptophan-related molecule (discussed below).

Signal transduction and regulation. Class I genes include a putative transcriptional regulator (Rsc2661) and a gene (RSp0840) that encodes a methyl-accepting protein probably involved in perception and in transduction of a chemotactic signal. Class II includes hrpG (RSp0852), the OmpR-related transcriptional activator required for transcription of $h r p B$ (Brito et al. 1999). This observation confirms our previous data indicating the existence of a regulatory loop between the $h r p B$ and $h r p G$ regulatory genes (Genin et al. 1992). Additional regulatory proteins are found in Class III, including three activators (RSc1892, RSc1813, and RSp1377), a repressor (RSp0258), and a long operon (RSp0779-Rsp0792) possibly involved in the synthesis of an $\mathrm{N}$-acyl homoserine lactone and of a fatty acid precursor. This latter gene probably plays a role in the production of a molecule governing quorum sensing in $R$. solanacearum.

Acquisition and transport of exogenous compounds. An important outcome from this study is the demonstration that $h r p B$ plays a key role in the control of iron acquisition and uptake, since this gene is involved in the repression of two contiguous operons (RSp0413 through RSp0424) that control the production and uptake of the ferrisiderophore staphyloferrin B (Bhatt and Denny 2004), together with an additional siderophore receptor (RSp0100). Moreover, Class IV genes are organized in a cluster of two close operons (Rsc1805 to RSc1808) all probably involved in biosynthesis and uptake of another ferrisiderophore. Several genes (RSp1461-RSp1463, and RSc2200) encode components of additional unknown ABC transporters.

Other functions. Among Class II genes are two hemagglutinin-like proteins (RSc3162 and RSp1536) that could be involved in the attachment of the bacteria to plant cells, since previous studies have established that type IV pili are not the only structures involved in this process (Kang et al. 2002). This class also includes two transposases (RSc0893, RSp0093) and a spermidine synthase (RSp0825), the function of which in pathogenicity remains to be clarified. Class III includes three genes encoding proteins from two different bacteriophages (RSc1918, RSp1938, RSc3248), two operons with unknown functions (Rsc1942 to RSc1943 and RSc3219 to $\mathrm{RSc} 3220$ ), a pirin-like protein (RSc2208), and a possible phosphatidyl-synthase (RSc3378).

\section{DISCUSSION}

In this work, we have developed a pangenomic microarray for $R$. solanacearum based on 65- to 70-mer oligonucleotides, and we have used it to identify genes whose expression is dependent on $\mathrm{HrpB}$, the AraC-related transcriptional activator that plays a crucial role in the control of pathogenicity of this bacterium. We have also established the reliability of this tool for transcriptome analysis, since under the very highly stringent cutoff conditions that we used (fourfold ratio, $P<0.01$ ), we were able to detect 64 of the 70 previously known $h r p B$ regulated genes. This microarray allowed us to identify 133 additional $h r p B$-regulated genes: 79 are $h r p B$ up-regulated, 50 are $h r p B$ down-regulated, and four have a more complex regulation pattern. These genes have been categorized into four classes based on expression patterns and promoter structure. Among the new genes identified, 34 of 37 chosen as representative of each of the four classes were validated as being $h r p B$ regulated, using either $l a c Z$ reporter gene fusions or RT-PCR. It is interesting to note that some of the newly identified upregulated genes, such as PopP1 or RSp0882, had previously been reported as being independent of $h r p B$ for transcription when $l a c Z$ gene fusions were used to monitor their expression (Cunnac et al. 2004b; Lavie et al. 2002). Similarly, transcriptome analysis clearly confirms the $h r p B$-regulated status of several effectors, such as RSc0608 or RSc1356, for which only a minor differential in expression was observed between wild type and the $h r p B$ mutant strains, using gene fusions (Cunnac et al. 2004b), indicating therefore that, for certain genes, transcriptome analysis might be a more sensitive method than the use of transcriptional gene fusions. This could be due to difference in mRNA stability of chimeric transcripts or stability of the chimeric LacZ reporter protein.

Concerning the distribution of $h r p B$-regulated genes over the genome, it is striking that both up- and down-expressed genes are overrepresented on the megaplasmid (120 genes for a total size of $2.1 \mathrm{Mb}$ ) as compared with the chromosome (77 genes for a total size of $3.7 \mathrm{Mb}$ ) and that this applies to genes encoding both TTSS-related and TTSS-independent functions.

\section{The Hrp regulon extends beyond TTSS-dependent functions.}

The amino-acid composition of the $\mathrm{N}$-terminal ends of more than one third of proteins encoded by Class I and Class II genes, including a majority of new proteins with unknown function identified in this study, indicates that these proteins are most likely secreted through the TTSS. These proteins are therefore good candidate effectors or TTSS-accessory proteins involved in the construction or in the functioning of the TTSS. Lysozyme-related transglycosylases are good examples of such potential accessory components. Based on the present experiments, we estimate that 70 to 80 effectors or TTSS-accessory proteins are encoded within the genome of strain GMI1000 and that more than 150 genes (including hrp genes) are positively controlled by $h r p B$, whereas more than 50 are negatively affected by this gene.

Most surprisingly, new genes identified in this study also include genes that encode proteins that are not directly involved in the functioning of the TTSS but might be implicated in virulence. An interesting example is the gene cluster $\mathrm{RSp} 0693$ to RSp0698 that is located $200 \mathrm{~kb}$ away from the hrp gene cluster of GMI1000. Interestingly, we found that the six proteins encoded within this $h r p B$-activated operon are highly conserved in another plant pathogen, Xanthomonas campestris pv. campestris (da Silva et al. 2002). Moreover, these six genes have a similar genetic organization in the two organisms, except that, in X. campestris pv. campestris, the gene orthologous to Rsp0694 is interrupted by an insertion sequence (Fig. 3). The homology is also visible at the DNA level, with a nucleotide conservation of more than $80 \%$ over most of the operon. Intriguingly, in X. campestris pv. campestris, this operon is located within the hrp pathogenicity island, $3 \mathrm{~kb}$ upstream of the $h r p F$ gene, which is a good indication that these genes might play a role in virulence. So far, an analogous operon has not been identified in any of the other completely sequenced genomes, including $X$. axonopodis pv. citri. These genes encode enzymes predicted to be involved in the putative bioconversion of a tryptophanrelated molecule. One possibility is that these genes could be responsible for the production of a toxin. If so, this situation is reminiscent of that found in Pseudomonas syringae, where syringomycin production is coregulated with TTSS activation 
through dependence on the alternative sigma factor encoded by the hrpL gene (Fouts et al. 2002). Alternatively, these genes could be involved in the production of a small diffusible molecule active on plants, like the avrD gene cluster from Pseudomonas syringae, which controls the synthesis of C-glycosyl lipids interacting with plants under hrpL dependence (Shen and Keen 1993; Smith et al. 1993). Yet another hypothesis is that this operon could be involved in the degradation of a toxic compound produced by the plant, such as camalexin, a tryptophan-derived phytoalexin produced by Arabidopsis thaliana (Glawischnig et al. 1993). In conclusion, our study demonstrates that the $h r p B$ regulon controls several functions involved in intermediate metabolism and transport of exogenous molecules.

Recently, using a promoter trap strategy to perform a systematic search for $h r p B$ up-regulated genes in strain MAFF30103 of $R$. solanacearum, Mukaihara and associates (2004) identified 30 new hrpB-activated genes, 20 of which were also detected in the present study. Interestingly, two of these genes classify in Class II in our study, whereas they are reported to be preceded by a $h r p B$ box in strain MAFFF30103, indicating that, in the two strains, evolution might have led to similar expression patterns using different regulatory pathways.

On the other hand, very little overlap was found between genes identified in our study and a large set of genes identified in an in vivo expression technology (IVET) approach (Brown and Allen 2004) as being required for multiplication of bacteria within the plant. However, it should be noted that this IVET approach identified very few hrp and related effector genes, suggesting that this methodology might target functions required at a later stage in the infection process.

\section{$h r p B$ has a dual regulatory role.}

We have demonstrated that $h r p B$ not only acts to promote expression of genes but that it also negatively affects expression of other genes. This had never been reported before, although it is now established in other organisms that some regulators of the AraC family can act both as activators and repressors (Egan 2002; Plano 2004). The presence of a $h r p_{I I}$ box in the promoter of genes from Class I is a good indication that the HrpB protein is directly involved in the regulation process, but the situation is more complex for Class II genes which are devoid of the $h_{r p}$ II box motif and are still $h r p B$-regulated. Since several transcription factors acting as activators (RSc1892 and RSp1377) or as repressor (RSc2661) have been identified among $h r p B$-regulated genes, it is possible that these genes could be intermediate regulatory genes mediating $h r p B$ dependent gene expression. Alternatively, it cannot be ruled out that the effect of $h r p B$ on gene expression could even result from other indirect effects.

\section{HrpB as a possible switch controlling transition from saprophytic to parasitic life.}

Our data indicate that the bacteria undergo a dramatic metabolic shift in the early stage of the infection process, in order to switch from saprophytic life in the soil to parasitic life in the plant. The dual action of $h r p B$ to promote up or down expression of different sets of genes, the diversity of biological functions that are controlled by this gene, and the diversity of environmental signals, including plant signals, metabolic status of the bacteria (Aldon et al. 2000; Brito et al. 1999; Marenda et al. 1998), and bacterial cell density integrated in the early stages of plant infection, suggest that this process can be considered a developmental program. It seems likely that Class III of hrpB-repressed genes, which includes a large number of genes putatively involved in the production of siderophores, may be not essential for pathogenicity but rather be important for the survival of the bacterium in the soil. The recent characterization of a strain carrying a mutation in the Class III gene RSp0424 and defective for the production of the siderophore staphyloferrin B revealed that, despite being almost incapable of scavenging iron, this mutant remained normally virulent on tomato plants (Bhatt and Denny 2004). A conclusion from the study of Bhatt and Denny (2004) is that $R$. solanacearum does not produce siderophore activity when cultured in tomato xylem sap that is iron replete, implying therefore that siderophore production is certainly more important in the rhizosphere to allow the pathogen to compete with other soil microbes for iron. Here we show that elevated amounts of HrpB in the cell (i.e., early steps of plant infection) lead to a repression of the genes involved in staphyloferrin B production (RSp0416 to

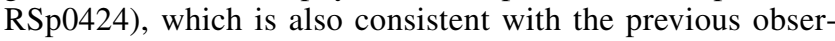
vation.

Taken altogether, our data thus indicate that the regulatory circuits previously described merit further investigation to include regulators acting downstream and upstream of $h r p B$ as well as their corresponding target genes. Further transcriptome analysis based on the use of mutants affected in these regulatory genes will help to clarify the status of the different classes of $h r p B$-regulated genes.

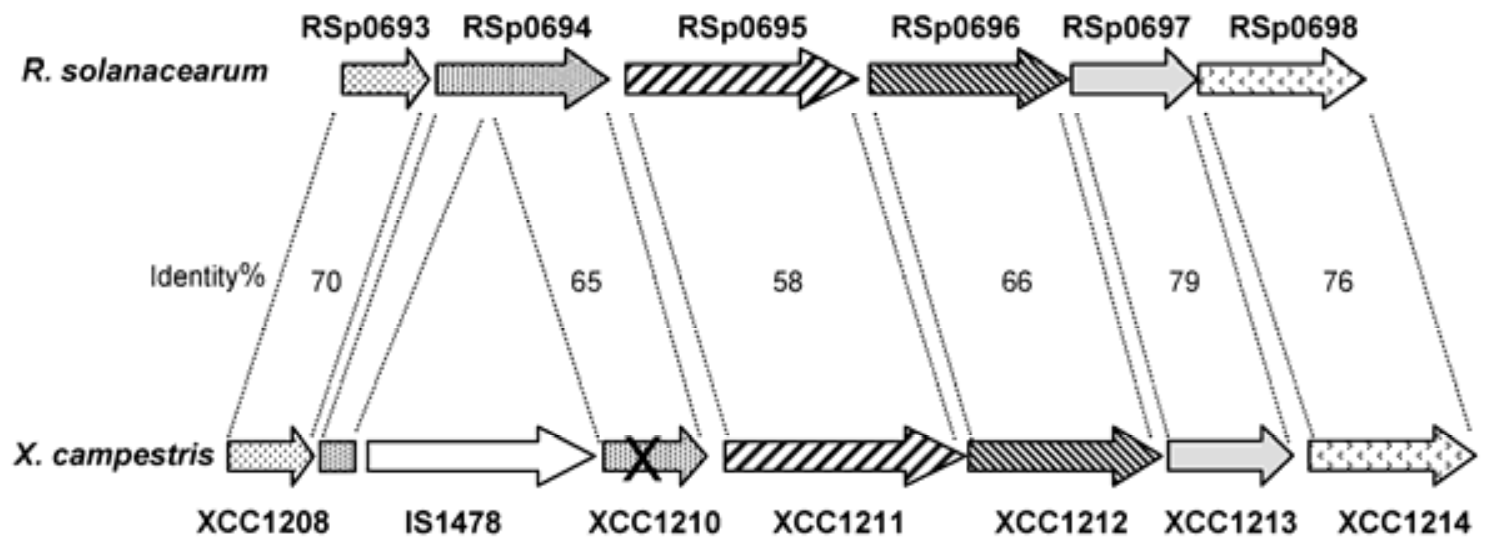

Fig. 3. Comparative organization of the RSp0693 to Rsp0698 gene cluster from Ralstonia solanacearum and the homologous gene cluster in Xanthonmonas campestris pv. campestris ATCC33913. Identity between the different genes is given at the protein level. The insertion sequence IS1478 is inserted within gene coding for a nonfunctional X. campestris pv. campestris 1210 gene. Gene nomenclature is according to Salanoubat and associates (2002) and da Silva and associates (2002) for X. campestris pv. campestris. 


\section{MATERIALS AND METHODS}

\section{Strains and growth conditions.}

The wild-type strain GMI1000 of $R$. solanacearum and its hrpB-derivative GMI1525 have been previously described (Boucher et al. 1985; Genin et al. 1992). Strain GMI1525 pLAFR3 was obtained by electroporation of GMI1525 with the empty vector pLAFR3 (Staskawicz et al. 1987). Strain GMI1728 is a derivative of strain GMI1000 that carries the plasmid pAM5, which harbors a cloned copy of $h r p B$ (Guéneron et al. 1999). Conditions for routine culture of E. coli and R. solanacearum have been described (Cunnac et al. 2004a). When required, antibiotics were used at the following concentrations $(\mu \mathrm{g} / \mathrm{ml})$ : ampicillin, 100; tetracycline, 10; and spectinomycin, 40.

\section{Nucleic acid extraction and semiquantitative RT-PCR.}

Genomic DNA used as template in PCR reactions was isolated from $R$. solanacearum GMI1000 cells cultured in complete BG liquid medium (Boucher et al. 1985), using a Wizard DNA genomic purification kit (Promega, Madison, WI, U.S.A.).

For RNA extraction, $R$. solanacearum bacteria were grown in logarithmic phase in 1-liter Erlenmeyer flasks on a rotary shaker at $50 \mathrm{rpm}$ in $100 \mathrm{ml}$ of liquid minimal medium MM (Boucher et al. 1985) until they reached an optical density at $600 \mathrm{~nm}\left(\mathrm{OD}_{600}\right)=0.8$, with $20 \mathrm{mM}$ glutamate as carbon source. The culture was immediately mixed with 0.05 vol of a cold solution of phenol/ethanol (10\% phenol in $95 \%$ ethanol) and was harvested by centrifugation $(4,600 \times g, 20 \mathrm{~min})$. RNA was extracted using the Qiagen RNeasy midi kit (Qiagen, Valencia, CA, U.S.A.), was concentrated by ethanol precipitation, and was treated with RNAase free DNAase I (Ambion, Austin, TX, U.S.A.) according to the manufacturer's recommendations. Purified total RNA was stored at $-80^{\circ} \mathrm{C}$.

Semiquantitative RT-PCR. Validation of microarray results by semiquantitative RT-PCR was performed on at least two independent biological experiments as described earlier (Cunnac et al. 2004b).

Quantitative RT-PCR. Aliquots of the cDNA samples used for the semiquantitative RT-PCR experiments were used for quantitative reverse transcription-mediated real time PCR. The Light Cycler (Roche, Branchburg, NJ, U.S.A.) with SYBR green chemistry was used to monitor amplification and to quantify the amount of PCR products (Roche). The RSc2690 gene, constitutively expressed (discussed below), was used to normalize expression values for all other genes. The popA gene was used as a control for $h r p B$-regulated genes.

\section{Microarray techniques.}

Primer design and pangenomic microarray construction. The pattern of the $R$. solanacearum whole-genome oligo arrays was based on the sequenced genome of $R$. solanacearum GMI1000 (Salanoubat et al. 2002). The 5,086 5' aminated oligomers were designed using the ROSO program (Reymond et al. 2004) and were purchased from Sigma Genosys (Saint Quentin Fallavier, France). The length of the gene-specific sequence was a $70(n=3,818)$ or a $65(n=1,260)$ mer and was chosen to be specific for the coding strand of each individual gene and as close as possible to the $5^{\prime}$ end of the gene. However, when some ambiguity remained concerning the possible start codon of a gene, the sequence was chosen downstream of the most distal candidate start codon. In a few cases $(n=8)$, the length was reduced to 60 mers to increase specificity or to prevent the formation of undesirable secondary structures. The sequence of each oligomer, together with its individual best BLAST score on a nonhomologous region of the GMI1000 genome and the free energy of secondary structures, can be provided on request. Each oligonucleotide was adjusted to 25 $\mu \mathrm{M}$ in $150 \mathrm{mM}$ sodium phosphate buffer $\left(\mathrm{Na}_{2} \mathrm{HPO}_{4}, \mathrm{pH} 9.0\right)$ and was spotted in duplicate, using a robot Eurogridder (ESI/Eurogentec, Seraing, Belgium) on aldehyde-activated glass slides prepared and treated according to Trévisiol and associates (2003).

\section{mRNA extraction.}

Expression profiles were generated using $100 \mathrm{ml}$ of bacteria grown in minimal medium to an $\mathrm{OD}_{600}=0.8$, conditions that are known to induce expression of $h r p B$-regulated functions (Genin et al. 1992). For each condition, two independent RNA preparations from two independent cultures were used. The bacterial cultures were treated by adding $5 \mathrm{ml}$ of a solution of $5 \%$ phenol in ethanol prior to centrifugation to kill the cell and to prevent any further transcription during that step. Lysis and RNA extraction was performed with the RNeasy midi kit from Qiagen according to the manufacturer's instructions.

Probe labeling and microarray slide hybridization. The mRNA were converted to cDNA and labeled with $\mathrm{Cy} 3$ or Cy5 fluorescent dyes (Amersham Biosciences, Buckinghamshire, U.K.), using a two step protocol according to Ruberg and associates (2003). For each mRNA, Cy3 and Cy5 labeling were performed in order to allow dye swap for each experiment. Total RNA was first converted to cDNAs in the presence of aminoallyl-dUTP using Superscript II reverse transcriptase (Invitrogen, Carlsbad, CA, U.S.A.). Total RNA $(25 \mu \mathrm{g})$ was combined with $6 \mu \mathrm{g}$ of random hexamers (Invitrogen) and was incubated at $70^{\circ} \mathrm{C}$ for $10 \mathrm{~min}$. After rapid cooling at $4^{\circ} \mathrm{C}$ for 30 $\mathrm{s}$, the reaction mixture was brought to a final volume of $30 \mu \mathrm{l}$ by adding $6 \mu \mathrm{l}$ of $5 \times$ Superscript II reverse transcriptase buffer, $3 \mu \mathrm{l}$ of $0.1 \mathrm{mM}$ dithiothreitol, $0.5 \mu \mathrm{l}$ of RNasin, $0.6 \mu \mathrm{l}$ of a $50 \times$ dNTP-ammino allyl dUTP mixture $(0.5 \mathrm{M}$ each of dGTP, dATP, and dCTP, $0.16 \mathrm{mM}$ dTTP, $0.34 \mathrm{mM}$ aminoallyl-dUTP), and $2.5 \mu \mathrm{l}$ of Superscript II reverse transcriptase. After incubation at $25^{\circ} \mathrm{C}$ for $10 \mathrm{~min}$, the mixture was kept at $45^{\circ} \mathrm{C}$ for $2 \mathrm{~h}$. After completion of the first-strand synthesis, the RNA was hydrolyzed by adding $15 \mu \mathrm{l}$ of $0.2 \mathrm{~N} \mathrm{NaOH}$ and incubating for $10 \mathrm{~min}$ at $70^{\circ} \mathrm{C}$. Neutralization was performed by adding $15 \mu \mathrm{l}$ of $0.2 \mathrm{~N} \mathrm{HCl}$. The aminoallyl-cDNA was purified from free amines and unincorporated aminoallyl-dUTP, using Qiaquick PCR spin columns (Qiagen). After elution, the aminoallylcDNA was dried under vacuum in a SpeedVac and was resuspended in $5 \mu \mathrm{l}$ of $1 \mathrm{M}$ sodium carbonate (pH 9.0). For fluorochrome labeling, $5 \mu \mathrm{l}$ of a solution of fluoroLink Cy3 or Cy5 dye, prepared by resuspending one reaction vial into $45 \mu \mathrm{l}$ of dimethyl sulfoxide, were added and incubated for $1 \mathrm{~h}$ at room temperature in the dark. This reaction was quenched by adding $5 \mu \mathrm{l}$ of $4 \mathrm{M}$ hydroxylamine and incubating for $15 \mathrm{~min}$ at room temperature in the dark. Fluorescent-labeled cDNAs were purified using Qiaquick PCR spin columns and were eluted in $30 \mu \mathrm{l}$ of the manufacturer's EB buffer. The two fluor-labeled cDNAs were then combined and concentrated to a volume of $35 \mu l$, using a SpeedVac.

Hybridizations were conducted using a Lucidea automated slide processor (Amersham Pharmacia Biotech, Piscataway, NY, U.S.A.) under the following conditions. Microarray slides were prehybridized for $1 \mathrm{~h}$ at $42^{\circ} \mathrm{C}$ in Dig Easy buffer (Roche) containing $10 \mu \mathrm{M}$ of salmon sperm DNA. Hybridizations were done for $13 \mathrm{~h}$ under the same conditions, except that the heatdenatured probes were added to the reaction mixture. Following hybridization, slides were washed once in $2 \times$ SSC $(1 \times$ SSC is $0.15 \mathrm{M} \mathrm{NaCl}$ plus $0.015 \mathrm{M}$ sodium citrate), $0.1 \%$ sodium dodecyl sulfate for $5 \mathrm{~min}$ at $60^{\circ} \mathrm{C}$ and two times in $0.1 \times \mathrm{SSC}$ for $1 \mathrm{~min}$ at room temperature and then washed in ethanol and dried at $37^{\circ} \mathrm{C}$ for $5 \mathrm{~min}$. 
Hybridized slides were scanned using GenePix 4000B dualchannel confocal laser scanner (Axon Instruments, Union City, CA, U.S.A.).

Data analysis. Signal quantification and data analysis were achieved using Imagene (version 5.6.1) and GeneSight software (version 4.1) (Biodiscovery Inc., El Segundo, CA, U.S.A.). Following local background subtraction, the signal for each spot was normalized based on the median value of the median intensity of all the spots for each array. Only genes for which the hybridization signal was greater than the average value plus two standard deviations of the negative controls (Corynebacterium glutamicum genes and non-GMI1000 DNA) were analyzed. The two signals corresponding to the two replicates present on the same slide were averaged and were used to calculate the ratio of expression between the $h r p B$-expressing strain and the $h r p B$-deficient mutant $\left(h r p^{+} / h r p B^{-}\right)$. Each ratio was converted to its $\log _{2}$ value, and the average $\log _{2}$ value for each gene of the four independent slides corresponding to each experiment was calculated (Table 1). Statistical significance of the gene expression differential over the course of the replicate experiments was calculated by using a Student's $t$ test analysis available in GeneSight software.

Only genes with high levels of significance $(P<0.01)$ and a minimum absolute value of $\log _{2}>2$ were systematically considered in this study, in order to minimize the false positive as up- or down-regulated. This threshold value was chosen as being highly discriminative for a high proportion of the previously known $h r p B$-regulated genes.

All primary data from transcriptome experiments as well as experimental protocols used are available from the ArrayExpress depository (accession numbers A-MEXP-152, E-MEXP262, and E-MEXP-263).

\section{ACKNOWLEDGMENTS}

This work was supported by the Institut National de la Recherche Agronomique (INRA), the Centre National Recherche Scientifique, and Toulouse Genopole. A. Occhialini was supported by a postdoctoral grant from INRA. We are grateful to D. Capela and C. Bruand for useful discussions regarding microarrays technology; $\mathrm{H}$. Charles for the design of oligonucleotides, V. Le Berre-Anton for the spotting of microarrays; S. Sokol for his help on the handling and analysis of transcriptome data; C. Balagué for her help in quantitative RT-PCR and P. Barberis for technical assistance.

\section{LITERATURE CITED}

Aldon, D., Brito, B., Boucher, C., and Genin, S. 2000. A bacterial sensor of plant cell contact controls the transcriptional induction of Ralstonia solanacearum pathogenicity genes. EMBO (Eur. Mol. Biol. Organ.) J. 19:2304-2314.

Alfano, J. R., and Collmer, A. 2004. Type III secretion system effector proteins: Double agents in bacterial disease and plant defense. Annu. Rev. Phytopathol. 42:385-414.

Arlat, M., Van Gijsegem, F., Huet, J. C., Pernollet, J. C., and Boucher, C. A. 1994. PopA1, a protein which induces a hypersensitivity-like response on specific Petunia genotypes, is secreted via the Hrp pathway of Pseudomonas solanacearum. EMBO (Eur. Mol. Biol. Organ.) J. 13:543-553.

Bhatt, G., and Denny, T. P. 2004. Ralstonia solanacearum iron scavenging by the siderophore staphyloferrin B is controlled by PhcA, the global virulence regulator. J. Bacteriol. 186:7896-7904.

Boucher, C. A., Barberis, P. A., Trigalet, A. P., and Démery, D. A. 1985. Transposon mutagenesis of Pseudomonas solanacearum: Isolation of Tn5-induced avirulent mutants. J. Gen. Microbiol. 131:2249-2457.

Brito, B., Marenda, M., Barberis, P., Boucher, C., and Genin, S. 1999. prhJ and $h r p G$, two new components of the plant signal-dependent regulatory cascade controlled by PrhA in Ralstonia solanacearum. Mol. Microbiol. 31:237-251.

Brown, D. G., and Allen, C. 2004. Ralstonia solanacearum genes induced during growth in tomato: An inside view of bacterial wilt. Mol. Microbiol. 53:1641-1660.

Buttner, D., and Bonas, U. 2002. Getting across-Bacterial type III effec- tor proteins on their way to the plant cell. EMBO (Eur. Mol. Biol. Organ.) J. 21:5313-5322.

Cunnac, S., Boucher, C., and Genin, S. 2004a. Characterization of the cisacting regulatory element controlling $\mathrm{HrpB}$-mediated activation of the type III secretion system and effector genes in Ralstonia solanacearum. J. Bacteriol. 186:2309-2318.

Cunnac, S., Occhialini, A., Barberis, P., Boucher, C., and Genin, S. 2004b. Inventory and functional analysis of the large Hrp regulon in Ralstonia solanacearum: Identification of novel effector proteins translocated to plant host cells through the type III secretion system. Mol. Microbiol. 53:115-128.

da Silva, A. C., Ferro, J. A., Reinach, F. C., Farah, C. S., Furlan, L. R., Quaggio, R. B., Monteiro-Vitorello, C. B., Van Sluys, M. A., Almeida, N. F., Alves, L. M., do Amaral, A. M., Bertolini, M. C., Camargo, L. E., Camarotte, G., Cannavan, F., Cardozo, J., Chambergo, F., Ciapina, L. P., Cicarelli, R. M., Coutinho, L. L., Cursino-Santos, J. R., El-Dorry, H., Faria, J. B., Ferreira, A. J., Ferreira, R. C., Ferro, M. I., Formighieri, E. F., Franco, M. C., Greggio, C. C., Gruber, A., Katsuyama, A. M., Kishi, L. T., Leite, R. P., Lemos, E. G., Lemos, M. V., Locali, E. C., Machado, M. A., Madeira, A. M., Martinez-Rossi, N. M., Martins, E. C., Meidanis, J., Menck, C. F., Miyaki, C. Y., Moon, D. H., Moreira, L. M., Novo, M. T., Okura, V. K., Oliveira, M. C., Oliveira, V. R., Pereira, H. A., Rossi, A., Sena, J. A., Silva, C., de Souza, R. F., Spinola, L. A., Takita, M. A., Tamura, R. E., Teixeira, E. C., Tezza, R. I., Trindade dos Santos, M., Truffi, D., Tsai, S. M., White, F. F., Setubal, J. C., and Kitajima, J. P. 2002. Comparison of the genomes of two Xanthomonas pathogens with differing host specificities. Nature 417:459-463.

Egan, S. M. 2002. Growing repertoire of AraC/XylS activators. J. Bacteriol. 184:5529-5532.

Fouts, D. E., Abramovitch, R. B., Alfano, J. R., Baldo, A. M., Buell, C. R., Cartinhour, S., Chatterjee, A. K., D’Ascenzo, M., Gwinn, M. L., Lazarowitz, S. G., Lin, N. C., Martin, G. B., Rehm, A. H., Schneider, D. J., van Dijk, K., Tang, X., and Collmer, A. 2002. Genomewide identification of Pseudomonas syringae pv. tomato DC3000 promoters controlled by the HrpL alternative sigma factor. Proc. Natl. Acad. Sci. U.S.A. 99:2275-2280.

Genin, S., and Boucher, C. A. 2004. Lessons learned from the genome analysis of Ralstonia solanacearum. Annu. Rev. Phytopathol. 42:107134.

Genin, S., Gough, C. L., Zischek, C., and Boucher, C. A. 1992. Evidence that the $h r p B$ gene encodes a positive regulator of pathogenicity genes from Pseudomonas solanacearum. Mol. Microbiol. 6:3065-3076.

Glawischnig, E, Hansen, B. G., Olsen, C. E., and Halkier, B. A. 2004. Camalexin is synthesized from indole-3-acetaldoxime, a key branching point between primary and secondary metabolism in Arabidopsis. Proc. Natl. Acad. Sci. U.S.A. 101:8245-8250.

Gonzalez, E. T., and Allen, C. 2003. Characterization of a Ralstonia solanacearum operon required for polygalacturonate degradation and uptake of galacturonic acid. Mol. Plant-Microbe Interact. 16:536-544.

Grigoriev, A. 2001. A relationship between gene expression and protein interactions on the proteome scale: Analysis of the bacteriophage T7 and the yeast Saccharomyces cerevisiae. Nucleic Acids Res. 29:35133519.

Guéneron, M., Timmers, A. C., Boucher, C., and Arlat, M. 2000. Two novel proteins, PopB, which has functional nuclear localization signals, and PopC, which has a large leucine-rich repeat domain, are secreted through the hrp-secretion apparatus of Ralstonia solanacearum. Mol. Microbiol. 36:261-277.

Hayward, A.C. 2000. Ralstonia solanacearum Pages 32-42 in: Encyclopedia of Microbiology Vol. 4. J. Lederberg, ed. Academic Press, San Diego, CA, U.S.A.

Kang, Y., Liu, H., Genin, S., Schell, M. A., and Denny, T. P. 2002. Ralstonia solanacearum requires type 4 pili to adhere to multiple surfaces and for natural transformation and virulence. Mol. Microbiol. 46:427-437.

Laub, M. T., McAdams, H. H., Feldblyum, T., Fraser, C. M., and Shapiro, L. 2000. Global analysis of the genetic network controlling a bacterial cell cycle. Science 290:2144-2148.

Lavie, M., Shillington, E., Eguiluz, C., Grimsley, N., and Boucher, C. 2002. PopP1, a new member of the YopJ/AvrRxv family of type III effector proteins, acts as a host-specificity factor and modulates aggressiveness of Ralstonia solanacearum. Mol. Plant-Microbe Interact. 15:1058-1068.

Marenda, M., Brito, B., Callard, D., Genin, S., Barberis, P., Boucher, C., and Arlat, M. 1998. PrhA controls a novel regulatory pathway required for the specific induction of Ralstonia solanacearum hrp genes in the presence of plant cells. Mol. Microbiol. 27:437-453.

Mukaihara, T., Tamura, N., Murata, Y., and Iwabuchi, M. 2004. Genetic screening of Hrp type III-related pathogenicity genes controlled by the HrpB transcriptional activator in Ralstonia solanacearum. Mol. Microbiol. 54 :853-875. 
Noël, L., Thieme, F., Nennstiel, D., and Bonas, U. 2001. cDNA-AFLP analysis unravels a genome-wide $h r p G$-regulon in the plant pathogen Xanthomonas campestris pv. vesicatoria. Mol. Microbiol. 41:1271-1281.

Plano, G. V. 2004. Modulation of AraC family member activity by protein ligands. Mol. Microbiol. 54:287-290.

Prior, P., Allen, C., and Elphinstone, J. 1997. Bacterial wilt disease. Springer-Verlag, Berlin.

Reymond, N., Charles, H., Duret, L., Calevro, F., Beslon, G., and Fayard, J. M. 2004. ROSO: Optimizing oligonucleotide probes for microarrays. Bioinformatics 20:271-273.

Ruberg, S, Tian, Z. X., Krol, E., Linke, B., Meyer, F., Wang, Y., Puhler, A., Weidner, S., and Becker, A. 2003. Construction and validation of a Sinorhizobium meliloti whole genome DNA microarray: Genome-wide profiling of osmoadaptive gene expression. J. Biotechnol. 106:255-268.

Salanoubat, M., Genin, S., Artiguenave, F., Gouzy, J., Mangenot, S., Arlat, M., Billault, A., Brottier, P., Camus, J. C., Cattolico, L., Chandler, M., Choisne, N., Claudel-Renard, C., Cunnac, S., Demange, N., Gaspin, C., Lavie, M., Moisan, A., Robert, C., Saurin, W., Schiex, T., Siguier, P., Thebault, P., Whalen, M., Wincker, P., Levy, M., Weissenbach, J., and Boucher, C. A. 2002. Genome sequence of the plant pathogen Ralstonia solanacearum. Nature 415:497-502.

Schell, M. A. 2000. Regulation of virulence and pathogenicity genes in Ralstonia solanacearum by a complex network. Annu. Rev. Phytopathol. 38:263-292.

Shen, H., and Keen, N. T. 1993. Characterization of the promoter of avirulence gene D from Pseudomonas syringae pv. tomato. J. Bacteriol. 175:5916-5924.
Smith, M. J., Mazzola, E. P., Sims, J., Midland, S., Keen, N. T., Burton, V., and Stayton, M. M. 1993. The syringolides: Bacterial C-glycosyl lipids that trigger plant disease resistance Tetrahedron Lett. 34:223226.

Staskawicz, B., Dahlbeck, D., Keen, N., and Napoli, C. 1987. Molecular characterization of cloned avirulence genes from race 0 and race 1 of Pseudomonas syringae pv. glycinea. J. Bacteriol. 169:5789-5794.

Trévisiol, E., Le Berre-Anton, V., Leclaire, J., Pratviel, G., Caminade, A. M., Majoral, J. P., François, J. M., and Meunier, B. 2003. Dendrislides, dendrichips: A simple chimical functionalization of glass slide with phosphorus dendrimers as an effective mean of preparation of biochips. New J. Chem. 27:1713-1719.

Van Sluys, M. A., Monteiro-Vitorello, C. B., Camargo, L. E., Menck, C. F., da Silva, A. C., Ferro, J. A., Oliveira, M. C., Setubal, J. C., Kitajima, J. P., and Simpson, A. J. 2002. Comparative genomic analysis of plantassociated bacteria. Annu. Rev. Phytopathol. 40:169-189.

Zwiesler-Vollick, J., Plovanich-Jones, A. E., Nomura, K., Bandyopadhyay, S., Joardar, V., Kunkel, B. N., and He, S. Y. 2002. Identification of novel hrp-regulated genes through functional genomic analysis of the Pseudomonas syringae pv. tomato DC3000 genome. Mol. Microbiol. 45:12071218.

\section{AUTHOR-RECOMMENDED INTERNET RESOURCE}

European Bioinformatics Institute's ArrayExpress depository: www.ebi.ac.uk/arrayexpress 